\title{
CONVERGENCE AND MULTIDISCIPLINARITY IN NANOTECHNOLOGY: LABORATORIES AS TECHNOLOGICAL HUBS
}

\author{
Nicolas Battard \\ Dublin Institute of Technology \\ Aungier Street \\ Dublin 2 \\ Ireland \\ Email: nico.battard@gmail.com
}

\begin{abstract}
This article argues that research groups dedicated to nanoscience and nanotechnology are considered as technological hubs where scientists with multiple backgrounds converge in order to conduct research at the nanoscale (a billionth of a metre). Scientific production is therefore challenged as multiple ways of thinking, practices and knowledge participate in the creation of new outcomes. Through an exploratory and inductive study, I show that these technological hubs develop a specialisation based on internal competencies and stock of knowledge. The specialisation enables laboratories to position themselves as an expert among other laboratories as well as making them more visible in order to attract funding. However, multidisciplinary research is hindered by knowledge and practices that are inherited from established scientific disciplines. The lack of standards and clear definition of the area of nanoscience and nanotechnology leads young scientists, $\mathrm{PhD}$ students particularly, to experience a misalignment between their research, their supervision, and the outcomes they have to produce.
\end{abstract}

Keywords: Nanotechnology, Scientific disciplines, Technological hub, Multidisciplinarity, Convergence 


\title{
INTRODUCTION
}

\begin{abstract}
At conferences it can be quite difficult when you are dealing with people who are purely in one area because you need to have knowledge of every area, you need to be able to discuss those areas with different people. So you do need to know a lot and you need to be very comfortable with the things that you know. So it is difficult. The nano field is quite difficult like that because we don't have a particular home like other scientists. (Comment from an interviewee, PhD student)
\end{abstract}

Nanotechnology is considered as an emerging and converging technology (Roco, 2008; Roco and Bainbridge, 2002) that is said to be one of the key technologies of the 21st century. Through an expansion of the label 'nanotechnology' (Grodal, 2007, 2010), multiple and diverse organisations and communities are gathered under this umbrella term. Nanotechnology is a young domain and encompasses disciplines such as applied physics, materials science, physical chemistry, physics of condensed matter, bio-chemistry and molecular biology, and polymer science and engineering (Heinze et al., 2007). These diverse sciences collaborate together in order, on the one hand, to understand the specific properties of the nanoparticles and to contribute to the scientific knowledge and on the other hand, to make new medical devices, more resistant materials and more efficient transistors (Bhat, 2005) among an unlimited number of other possibilities that are likely to change number of industries (Avenel et al., 2007). However, this scientific multidisciplinarity remains understudied.

Whereas scientific boundaries have been studied in the sociology of science (Gieryn, 1983, 1999), little attention has been given in management science to the convergence of multiple scientific disciplines around a technology and its organisational consequences. Indeed, scientometric studies suggest that nanotechnology is a set of overlapping scientific disciplines (Meyer, 2001, 2007) mainly driven by physics and chemistry (Bassecoulard et al., 2007; 
Schummer, 2004b). However, the understanding of what happens within this overlap is still understudied.

Following the problem-solving logic, specialisation tends to be the characteristic of modern sciences (Popper, 1970). Scientific disciplines are embedded in paradigms that condition the way of thinking, legitimise the practices and rule the scientific activity (Kuhn, 1970). Usually, when a new discipline emerges within a new paradigm, we witness the creation of degrees that are entirely dedicated to the new discipline, $\mathrm{PhD}$ programmes that hold the name of the new discipline, new applications, etc. However, nanotechnology seems to counter this scheme by integrating multiple scientific disciplines around the same technology. In this way, crossing scientific boundaries means to face other methods, practices, ways of thinking, etc. and thus to constrain the production of scientific outcomes. From these observations, I ask the following research question: How do scientists involved in a scientific area crossing multiple scientific disciplines use multidisciplinary knowledge in order to create a new scientific outcome?

To answer this research question, the study has been organised as follows. First, a point is made on what we can learn from the philosophy and the sociology of science and the categories that can be constructed from these disciplines in order to understand the sciences born after the Second World War (Bonaccorsi, 2008)such as nanotechnology. Second, from this framework and through a qualitative and exploratory study, I argue that laboratories are technological hubs through which scientists converge from multiple scientific backgrounds. As such, they have to be understood through the physical, social and cognitive boundaries that delineate them. Although they are working in the same laboratory and sometimes on the same project, scientists face cognitive barriers that constrain the collaboration between scientific disciplines. Finally, from the results, different issues are raised in order to question the 
evolution of the field of nanotechnology and the future researches that can be undertaken in order to highlight the specificity of the area of nanotechnology.

\section{BOUNDARIES AND MULTIDISCIPLINARITY IN SCIENCE}

\subsection{Scientific disciplines: An insight from philosophy and sociology of science}

According to Popper, science has to be falsifiable and must be falsified (1959). In other words, scientists must try to prove that their hypotheses are wrong instead of right in order to improve the research programme (or paradigm in the sense of Kuhn; both will be used in the same sense in this study). If a theory is tested and proved right through the process of falsification it has to be accepted and, conversely if it is proved wrong it has to be abandoned. Lakatos (1970) argued that core hypotheses are protected by a shield of auxiliary hypotheses which will be abandoned, improved or created. In this way, o ld research programmes are not necessarily destroyed by new ones. For instance, when Einstein discovered the theory of relativity, Newton's theory was not abandoned. It is still being used and improved. In

opposition to Kuhn, Popper and Lakatos showed that a new science can start without disrupting another. Moreover, modern sciences tend to follow a theoretical problem-solving approach and to be more and more specialised (Popper, 1970).

Kuhn (1970) argued that scientific disciplines are embedded in paradigms that condition the way of thinking, legitimise the practices and rule the scientific activity. He defined paradigms as a set of fundamental concepts and hypotheses, practices, methods and beliefs. Scientists do their everyday life activities oriented and guided by these rules without sometimes being able to define them precisely (Kuhn, 1970). Within these guidelines, scientists are in charge of testing all different hypotheses, improving the theory and providing the scientific community 
with a wider understanding of the world. That is what Kuhn named 'normal science.' The latter defines the boundaries of the scientific community within which practices are accepted by the community, scientific problems solved (Kuhn, 1970) and knowledge accumulated and shared (Merton, 1942: 268).

Sociology of science also gives sense to scientific boundaries. Boundary construction is a prerequisite for 'inner' scientists if they want the discipline to grow, to evolve and to become an established science which will be independent from states, industries and other scientific disciplines (Gieryn, 1983). First, boundaries are essential for scientists to pursue professional goals such as intellectual authority and career opportunities (Gieryn, 1983). Indeed, expert knowledge can only be claimed by a limited community of scientists. If accepted by every scientists, knowledge becomes tacit and is integrated into instruments (Latour, 1987). Second it is among an identified community that scientists can gain credit and climb up through the grades of the scientific hierarchy (Latour and Woolgar, 1979). Third, drawing boundaries enables the identification of fundamental knowledge, methods, ways of thinking, etc. that will be supported by institutions and taught in class in order to reproduce and to maintain the scientific community.

Within these boundaries, data is produced and artefacts trans-formed into facts in order to be published, accepted and thus objectivised to finally become the new reality of a specific scientific community. Latour (1987) argued that to understand the whole process, human and non-human actors have to be studied together. Indeed, the construction of scientific facts cannot be understood without taking into account the human actors who interpret the results, build arguments and write articles and those who use this article and thus participate to the diffusion of a new idea. Then, instruments are considered as 'black boxes' whereof results produced are legitimate given the instrument is acknowledged by the scientific community and is no longer a controversial issue. Instruments are not mere machines that transform 
through their pro-cesses the reality into charts, figures and graphics but also produce data which once accepted by the scientific community will be the scientific reality. The latter is built by scientists that use other scientists' arguments in order to build theirs. When the argument is accepted, it is transformed into tacit knowledge and incorporated into instruments which will bring this tacit knowledge into another scientific discipline.

To sum up, following the problem solving logic, specialisation tends to be the characteristic of modern science (Popper, 1970). Scientific disciplines are embedded in paradigms that condition the way of thinking, practices and rule the scientific activity (Kuhn, 1970).

\subsection{Multi- and interdisciplinarity in science}

Science has undergone significant changes in the past few decades. As described by the triple helix model (Leydesdorff, 2000; Leydesdorff and Etzkowitz, 1998; Leydesdorff and Meyer, 2007), boundaries between science, government and industry have been blurred. The view of homogeneous and closed scientific communities is challenged by recent works on a shift between two ways of doing science (Bonaccorsi, 2008 ; Bonaccorsi and Thoma, 2007; Gibbons et al., 1994; Nowotny et al., 2003). Described by Gibbons et al. (1994) as 'mode 1', old sciences, such as physics, chemistry, biology and their sub-disciplines, are characterised by disciplinary, university-based and government-based laboratories. 'Mode 2' describes sciences that are characterised by being multidisciplinary, based on networks of knowledge and oriented towards problem solving and societal challenges. Bonaccorsi (2008: 296) argues that new sciences are 'reductionist sciences that address new complex phenomena by breaking the boundary between natural and artificial.' They are measured through three different indicators. First, the rate of growth shows a constant entry of new fields that grow very quickly after entry and a high turnover rate. This contrasts with 'old' science whereof changes were paradigmatic and revolutionary, and normal science (Kuhn, 1970) characterised 
by a slow rate of growth. Second, the degree of diversity brings to light the difference between diversity before and after paradigmatic change and diversity within normal science and also questions t he number of directions that can be pursued at the same time. This indicator shows that new sciences generate new hypotheses within established paradigms with weak or strong divergence. This is very different to old sciences, where divergence was exceptional. Third, the level and type of complementarity show the process of crossdisciplinary competence building, new forms of infrastructural utilisation design or institutional cooperation. This last indicator is based on the structure of affiliation and institutional complementarities in publications. This shows that industrial affiliations as well as that of the number of occurrences with multiple research institutions and with companies is much higher in new sciences than old sciences.

These views of new sciences highlight the involvement of multiple scientific disciplines around the same object which is characterised either as multidisciplinary or interdisciplinary. First, multidisciplinarity involves at least two disciplines (Heinze and Bauer, 2007) and is described as 'a rather loose, additive or preliminary relation between the disciplines involved' (Schummer, 2004b: p. 11). In a multidisciplinary context, although different disciplines overlap which fosters wider knowledge, information and methods, disciplines remain separate from each other and the structure of knowledge is not questioned (Klein, 2010). Multidisciplinarity thus is a primary step towards interdisciplinarity that requires 'strong ties, overlap, or integration' (Schummer, 2004b: p. 11). So when interactions between at least two scientific disciplines become more proactive, the new area can be described as interdisciplinary. 


\subsection{Motivations and research question}

The use of the 1-100 nm scale to define nanoscience and nanotechnology $(\mathrm{N} \& \mathrm{~N})$ do not explain whether different established scientific disciplines are converging and what is happening when scientists with different backgrounds are converging. For instance, working with molecules is the purpose of chemistry (Grodal, 2007). Moreover, the convergence between scientific disciplines is not completely new and is still controversial. Material science, one of the disciplines crossed by nanotechnology, is the result of a convergence between physics and chemistry.

Different and disparate technological and scientific fields are converging towards N\&N (Avenel et al., 2007; Bozeman et al., 2007; Porter and Youtie, 2009). This convergence is said to 'fuse' the traditional disciplines (Islam and Miyazaki, 2009) in order to lead to a new area of research (Linstone, 2011). However, the reason of this convergence is still discussed. One the one hand, Loveridge et al. (2008) argue that the artefacts made at the nanoscale (nanoartefacts) are the basis of this convergence. One of the attributes of these nano-artefacts is to integrate multiple scientific and engineering disciplines; the other attributes being the 1-100 $\mathrm{nm}$ scale and a pervasive characteristic. On the other hand, Schmidt (2008) sees the convergence of different disciplines as a shared use of instruments such as atomic force microscopes or scanning tunnelling microscopes. So, in his view, it is less the particle or the device in itself that characterises the convergence than the different ways to produce them. Moreover, the view of a complete convergence towards a unified area of research has not yet reached consensus among the scholars.

Scientometric studies bring useful insights regarding the different controversies that nurture the discussion about the new area of N\&N. Schummer (2008) argues that there is no strong evidences for claiming a scientific revolution based on new tools. Indeed, scientometric 
studies, through citation and co-citation analysis, tend to show that the area of N\&N is more characterised by an aggregation of disconnected disciplines than a multidisciplinary convergence. $\mathrm{N} \& \mathrm{~N}$ does not reveal any particular patterns of interdisciplinarity and must be considered more as multiple mono-disciplinary scientific fields sharing the prefix 'nano' than a new unified area of research (Schummer, 2004a). So, although the word 'nano' has spread, boundaries of science have not really been challenged by this new technology.

Although on the one hand, there is a call for more interdisciplinary collaborations in $\mathrm{N} \& \mathrm{~N}$ by policy makers and on the other hand, scientometric studies balance the interdisciplinary characteristic of $\mathrm{N} \& \mathrm{~N}$, we do not know what happens in a laboratory where scientists with different backgrounds collaborate. The motivation of the study is twofold. First, although some studies have been done on the different types of scientific outcomes that a mono- or a multidisciplinary team can produce (Porac et al., 2004), little is understood about how a scientist uses knowledge from multiple disciplines in order to create a new outcome. Second, funding dedicated to $\mathrm{N} \& \mathrm{~N}$ has been increasing over time (Roco, 2005). Even if the deep nature of $\mathrm{N} \& \mathrm{~N}$ is not settled down as yet, into unrelated disciplines or a new single scientific discipline, nanotechnology has the potential to enhance nations' productivity (Roco and Bainbridge, 2002) and thus bring a serious competitive advantage to organisations that use, either in the process or in the product, technologies at the nanoscale. Dynamics that occur in these very specific organisations have to be better understood if they want to be fostered and developed. While multidisciplinary teams tend to produce more varied concepts than monodisciplinary ones (Porac et al., 2004), the determinants of the knowledge creation need to be better understood to enhance the comprehension of these knowledge-based organisations.

This study has been designed to deepen the knowledge on how scientists with different backgrounds produce scientific outcomes in a multidisciplinary context and how they experience this multidisciplinarity. Even though science and even scientific disciplines are 
difficult to be precisely defined, the theories mentioned earlier help to frame the different foci that are important to look at in this specific context. We first saw that scientific disciplines are embedded in paradigms (Kuhn, 1970) in order to enable knowledge accumulation (Merton, 1942/1973: 268). This is materialised by the different schools that teach students specific concepts, methods, way of thinking, etc. and that agree with the paradigms within which the disciplines are embedded; in Schummer's (2004b) words, 'a social context of transmission and education and a social body that thereby reproduces itself' (p. 11). However, these boundaries are not easy to transcend. Indeed, path-dependency research suggests that emotional reactions such as uncertainty avoidance, cognitive biases (selective perception, implicit theories) can lead to a lock-in situation (Sydow et al., 2009).

Rafols and Meyer (2007) give another view of interdisciplinarity in N\&N by arguing that cross-disciplinarity does exist in terms of 'cognitive practices', i.e. use of references and instruments, but much less in terms of affiliations and backgrounds of the researchers. In this way, scientists cite articles from other disciplines but regarding their collaboration, they tend to stay in their original discipline. I here refer to Weick (2003)to define practices as 'equated with doing, concreteness, understanding, know-how and wholes' (p. 454). So, within this framework, I focus on how multidisciplinary or interdisciplinary research is practiced and ask the following research question: How do scientists evolving in a scientific area crossing multiple scientific disciplines use multidisciplinary knowledge in order to create a new scientific outcome? The next part describes the methodology that has been followed and then findings will be presented and discussed. 


\section{METHODOLOGY}

\subsection{Case study research design}

This study meets the three criteria set up by Yin (2009) for which a case study design is suited. First, I focus here on a 'how' research question which aims at describing how scientists practise multidisciplinary research. Second and third, this study focuses on a contemporary event for which the behaviours cannot be manipulated. $N \& N$ is a young domain (Heinze et al., 2007) whereof the attributes such as multidisciplinarity is not fully understood yet. Next, the study took place in a laboratory — which will be described below — where scientists do their research on a daily basis.

\subsection{Research setting}

This case has been chosen for its endogenous attributes (Siggelkow, 2007). Indeed, the research group on which the study is based focuses its research on particles at the nanoscale and encompasses scientists with multiple scientific backgrounds. Studying a research group as a whole instead of experiments has been chosen because it allows consideration of "the full spectrum of activities involved in the production of knowledge' (Knorr Cetina, 1992: 115). I will first describe the research centre and then the research group which has been studied. The research centre was founded upon the basis of multidisciplinarity with the common denominator of optical characterisation and spectroscopy.

The research centre has been built thanks to a national grant for which the call was in 1999 . The objectives of this funding programme were to develop research capabilities, to give support to individual researchers and research teams and to foster the cooperation between and within institutions. In this way, the objectives of the proposal were based on extending the capabilities of the existing research groups but with the possibility to build new ones, on the 
construction of shared facilities and on the objective to develop interdisciplinarity at both the research and education levels. At, six research groups were defined and were clustered around the core laboratories. These research groups focused on radiation and environmental science, environmental chemistry, inorganic chemistry, physics of molecular materials, holographic research and solid state physics. In 2004, two main changes occurred. Firstly, two other groups were hosted in the building (one focusing on wireless communications and the other on engineering surface coating). The second change was the evolution and redefinition of the physics of molecular materials and solid state physics groups into two new groups: nanophysics and the sola $\mathrm{r}$ energy group. The increasing worldwide development of N\&N led the research centre to develop further knowledge in this area of expertise.

The drive to develop $\mathrm{N} \& \mathrm{~N}$ research resulted in the research centre introducing several activities at the nanoscale scattered in different groups. Building on internal competencies (biology and physical characterisation), managers of the research centre decided to focus on biological aspects of nanotechnology. In order to do this, the nanophysics group disappeared and, in 2008, a new group focusing on nanotoxicology and nanobio-interactions was created: Nanotoxlab (pseudonym). This group gathered together the different $\mathrm{PhD}$ students and post doctoral researchers that were doing research at the nanoscale under the discipline of nanobiointeractions and specifically nanotoxicology.

Nanotoxicology is an emerging sub-branch of toxicology which aims to study the impact of nanoparticles on human health and the environment (Oberdörster et al., 2005). Nanoparticles have the particularity to be able to traverse the cell membranes (Seaton and Donaldson, 2005) and thus lead to unexpected consequences. If non-toxic, these particles present properties that can be used in domains such as drug delivery or cancer therapy (De Jong and Borm, 2008). Scientists within Nanotoxlab not only study human cells but also extend their study over the whole food chain by analysing algae, fish, and mammalian cells, particularly human. 
Although this discipline is a sub-discipline of toxicology which is mainly a biological discipline, the first step of an experiment is to characterise the nanoparticle (defining size, shape, surface area, etc.) which involves physics and chemistry. Then, biology-related experiments are undertaken to test the nanoparticles in order to determine their characteristics and their toxic effects on different types of organisms and cells.

The laboratory is mainly divided into two spaces: physical and biological experiments. The first space, dedicated to physical experiments, includes instruments used to characterise size, shape and surface area of the nanoparticles. The second space, dedicated to biological experiments, includes separate rooms that are dedicated to the study of fish cells, mammalian cells or human cells. Both spaces can be used by all scientists in the conduct of their research. PhD students and postdoctoral researchers have very different backgrounds, such as physics, chemistry, biology and toxicology. Although the collaboration is limited between them, projects are multi-disciplinary, including physics - mainly physical characterisation - and biology. However, as the process is complex and the project is characterised as multidisciplinary, the steps between the different disciplines are identifiable.

\subsection{Data collection}

This study relies on two sources of data. The first source of data is archival documents. It includes a book that traces the history of the research centre from 1999 to 2006 and of the different grant proposals, reviews and presentations that are related to the development of Nanotoxlab. This helped to have a better understanding of the history of the research centre in which the research group is embedded, as well as how this new research group is developed and justified. The second and main source of data is based on 12 semi-structured and 11 structured interviews (see Table 1). The respondents were defined by their membership to Nanotoxlab. This research group is made of the manager of the research centre, one lecturer, 
two postdoctoral researchers and six $\mathrm{PhD}$ students. The manager of the radiation and environmental science group has been included into the study as she is deeply involved in a 11 biology-related experiments. Three steps have been followed.

The first step includes semi-structured interviews with the manager of the research centre and the lecturer. Questions were related to both the research centre and the Nanotoxlab in order to have a global understanding of the reasons why they decided to develop $N \& N$ within the centre and more particularly nanotoxicology. These interviews were conducted in order to fill the gaps and to add precisions to the information gathered with the archival documents.

The second step consists of the first round of interviews that were conducted with the manager of research centre, the lecturer, the two post doctoral researchers and the six $\mathrm{PhD}$ students. During this round of interviews, respondents were asked to talk about their research. To do so, they were asked to describe what tasks they are doing on a daily basis such as the type of journals they are reading, the different types of experiments they have done and need to do so for their research and their interactions with the other members of Nanotoxlab. Interviews were open-ended in order to let new themes emerge. This first round of interviews allowed the identification of global themes that were used to frame the second round of interviews. These themes were the vision they have of Nanotoxlab and the integration of different scientific disciplines. The open-end of the interviews allowed the emergence of the tensions that might occur on the one hand when they have to make an experiment which is outside their scientific background and on the other hand, when they collaborate with scientists that have a different scientific background from theirs.

The third step of interviews includes structured interviews that were conducted with the manager of the research centre, the research group manager, the lecturer, the two post doctoral researchers and the six $\mathrm{PhD}$ students. This approach was under-taken in order to compare the 
different themes between the interviews. These structured interviews were divided into three main parts. First, they were asked to describe their path from their undergraduate studies until their current position. Second, they were asked to describe Nanotoxlab and to explain what makes it different from another scientific laboratory dedicated to $N \& N$. Third, they were asked to describe their work by relating each step to a specific discipline. This has been done in order to understand to what extent their work is multidisciplinary. Then, they were asked the types of journals they are reading and citing, and the ones they are targeting. These questions were coupled with the conferences they are going to. Finally, they were asked to describe a collaborative experience (a simple experiment or a whole study). For each set of questions, an emphasis was given to the tensions they might have experienced.

The interviews were recorded and taped except one during the first round but for which notes were taken and transcribed the same day. The interviews lasted from 45 to $100 \mathrm{~min}$. All data were anonymised. When an interviewee referred to another laboratory and the quotes included in this study, names were replaced by Alpha, Beta and Gamma.

$<$ Please insert Table 1 about here>

\subsection{Data analysis}

Miles and Huberman (1994) advise that data collection and data analysis have to be intertwined from the start. Overlapping these two stages enables to fasten the analysis and to reveal adjustments to the collection of data (Eisenhardt, 1989). Although three steps were detailed in the data collection they were part of the data analysis and the emergence of the themes. The three steps define the adjustments in the data collection and the deepening of the 
under-standing of these three steps. To do so, an inductive approach has been used and for which I travelled back and forth between the data collection and the theoretical understanding (Glaser and Strauss, 1967). The three steps of data collection reflect the back and forth between data and emerging theories as well as the focus on more and more narrowed category. I integrated the coding schemes that were related to multidisciplinarity and scientific knowledge production. The coding scheme enabled me to keep focus on the research question that I sought to address: how do scientists evolving in a scientific area crossing multiple scientific disciplines use multidisciplinary knowledge in order to create a new scientific outcome? To answer the research question, I developed a list of first order codes and worked on this list in order to obtain non-repetitive statements. These open codes are made up of the words that the respondents used. These first order codes were then revised in order to generate aggregates that encompass the first order codes. They were finally gathered under key themes that structure the findings that are developed below: democratisation of the equipments, development of a specialisation in $\mathrm{N} \& \mathrm{~N}$ and finally, perception of the area of $\mathrm{N} \& \mathrm{~N}$.

\section{FINDINGS: SCIENTIFIC LABORATORIES AS TECHNOLOGICAL HUBS}

\subsection{Democratisation of the equipments}

Contrary to biotechnology, nanotechnology requires expensive equipment in order to be able to see, to manipulate and to control molecules at the nanoscale. These equipments have enabled all scientific disciplines to see at the nanoscale and thus to validate or to invalidate theories. However, in the 1980s and early 1990s, this type of equipment was very expensive and only reserved for big laboratories. So, even if the theory allowed scientists to have an understanding of the nanoscale, small laboratories were not able to conduct experiments. Then, Gerd Binnig and Heinrich Rohrer from IBM-Zurich in Switzerland won the Nobel 
Prize in 1986 for the invention of the scanning tunnelling microscope. After its commercialisation, small laboratories were also able to conduct experiments at the nanoscale. With the scanning tunnelling microscope (STM) and the atomic force microscope (AFM), two essential tools in nanotechnology, scientists are able to see and to manipulate single atoms. The democratisation of these two materials led laboratories to be equipped with tools enabling research at the nanoscale.

The atomic force microscope and the scanning tunnelling microscope have changed scientific disciplines, not by modifying their way of doing science or the internal scientific logic, but by bringing new possibilities that were just theoretical. So, physicists who traditionally had a topdown approach reached the level of the atom and thus were able to better understand the physical properties as well as to manipulate and thus to make materials. Although the term was not used, experiments at the nanoscale were already possible with these equipments. So, more than real breakthroughs, possibilities offered by this microscopy were a natural step in the scientific evolution.

\begin{abstract}
'In physical science, in physics and chemistry, it's more or less a continuum but the real huge step, the real revolution of under-standing was in 1910, 1920. I suppose from that came the AFM, the electron microscope, the atomic force microscope. From that came the ability to review everything. I think it was a huge step and since then everything has been increasing. And then, you have things like the AFM. That provides then some support for bio, for genetics. Suddenly being able to see and being able to manipulate, that kind of enables all the other disciplines. There was a huge step in the science, technology of course improved but there was nothing really that enables genetics. I would think that's the key enabler. It's not just AFM, STM, it's generally scanning probe. This enables to see and manipulate at the nanoscale.' (Manager of the research centre)
\end{abstract}

These instruments have challenged the scientific disciplines by enabling them either to confirm or to refute their theories. This technological breakthrough has challenged at the same time multiple disciplines by giving the scientists the possibility to 'push' their disciplines to the nanoscale. So, multiple scientific disciplines that had a theoretical understanding of the atom such as quantum physics could from now on conduct experiments at this scale. So, new scientific avenues of collaboration are possible. However, this technology has not disrupted 
all scientific paradigms and completely changed their interactions. Although equipments have enabled scientific disciplines to see, to manipulate and to control at the nanoscale, this has not made them melt into one single scientific discipline.

\subsection{Development of a specialisation in $N \& N$}

Nanotoxlab developed its specialisation in line with the groups and competencies that were previously available in the research centre. Indeed, they based the speciality of the research group on the radiation biology group and, the nanophysics group that was dissolved. Based on this internal stock of knowledge - characterisation of particles at the nanoscale and biological understanding of cell death - they developed the specialisation of the research group in the area of nanotoxicology. The development of a domain of expertise is linked with the need of being visible and to have cutting edge facilities. All three are linked together. Indeed, to perform research at the nanoscale, specific equipments such as atomic force microscopes, scanning electron microscopes, etc. are necessary. Although this type of equipment is available on the market and thus available to all laboratories, they remain expensive. So, laboratories have to resort to external funding in order to buy nano-related equipments.

As highlighted in the grant proposals, justifying the need for funding relies on the relevance of the work for science and society. In the case of Nanotoxlab, the relevance for the scientific community is described as a need for a better understanding of the properties of the nanoparticles and how they behave in cells. This lack of understanding is also relevant for society as nano-particles can potentially be harmful. In this way, risks have to be assessed. The project is justified by internal capabilities such as the scientists that are carrying on the project and their areas of expertise as well as previous publications in these scientific domains. Being visible in the area enhances the chance of the proposal being accepted. 
Publications justify the competencies of the scientists as being accepted by the scientific community and thus providing the latter with new and accepted knowledge (see Table 2).

Although the domain of expertise is influenced by public funding, the development of a speciality in the case of Nanotoxlab is also based on an internal stock of knowledge and competences.

<Please insert Table 2 about here>

\subsection{Scientific boundaries: between heritage and adaptation}

Scientific backgrounds are embedded in established scientific disciplines that provide scientists with guidance in their way of doing research (Kuhn, 1970) on the one hand, and enable scientists to identify and to locate themselves in a multidisciplinary environment on the other. Although Nanotoxlab hosted scientists from PhD students to professors that are every day in a multidisciplinary environment, they still perceived the boundaries that are inherent in their respective scientific education. This scientific heritage bounds the scientist into a way of thinking and methods. This is within this monodisciplinary embedment that a research can be part of the cumulative process of scientific knowledge production (Merton, 1942). In the case of Nanotoxlab, this scientific heritage can be identified when scientists with different backgrounds are collaborating on the same project. The different biases led by the theoretical foundations of a discipline, methods, vocabulary and so on, create boundaries that can hinder the creation of knowledge.

'That was the funniest thing. She wanted to work with ppm, particle per million. And this milligram, what the hell is a milligram, what you're talking. She thought we were insane. And she said how much the cell can actually receive. We couldn't tell her because all the 
other things that are going to happen in the process, and they all won't be the same size. The idea for us, we can blindly, well we don't blindly accept but we understood why our sample wouldn't be uniform.' (Post doctoral researcher and manager of the laboratory)

In a multidisciplinary project and collaboration, scientists have to locally adapt themselves in order to produce a new outcome. In the case of Nanotoxlab and more generally in the discipline of nanotoxicology, scientists have to first characterise the nanoparticles before testing its toxicity. This first step is essential as they can afterwards relate the properties of the particle to its toxic effect. In this way, the 'multidisciplinary label' is used by scientists when they integrate physical characterisation to a biological study. Depending on the instrument which is used to understand the properties of particles, the level of involvement in other scientific discipline can vary.

'It depends on the techniques you're using to characterise. If you're using something like a DLS, it's quite an automatic system. You prepare a solution quite easily, just by diluting nanoparticles and then you put into the machine and press go whereas if you're doing something like AFM or TEM or STM, there's a quite lot more of involvement in it.' (Post doctoral researcher)

Collaborating on a multidisciplinary project leads scientists to create local practices and adaptation. Methods are borrowed from established protocols in order to be validated and justified in another. However, in order to introduce physical knowledge in a biological paper, explanations cannot be reduced to the main references but have to be extended.

\footnotetext{
'Two reviewers said fine publish as it is and one reviewer basically wanted a greater explanation of the absorption-desorption. So we had to put the statement in the paper. From time of review, probably four and a half months from the start of the experiment and to get it published. That's was very quick but that was a very solid experiment, very simple but it showed a very strong effect. That was the only bad thing, the bad review. We presume, this person was a biologist and he didn't understand the experiments.' (Post doctoral researcher and manager of the laboratory)
}

When the level of involvement is high, it is compensated with extensive readings and, most of the time, by a return to the basics of the discipline. Although the development of knowledge from other disciplines eases the communication between scientists and thus improves multidisciplinary research, it also hinders the process of knowledge creation by limiting the accumulation process. 
'When I read papers and when I go to conferences and I see people working with the same cells as me and the same particles as me, they just seem to be always two steps ahead, even miles ahead.' (PhD student, background in applied chemistry)

Troubles in performing multidisciplinary research have mainly been expressed by $\mathrm{PhD}$ students. The lack of global vision of the area of N\&N and knowledge in a particular discipline raises two types of constraints. The first constraint is related to the super-vision of the $\mathrm{PhD}$. As they are supervised by scientists coming from one established discipline, $\mathrm{PhD}$ students that are doing their research in the area of $\mathrm{N} \& \mathrm{~N}$, and here in nanotoxicology, cannot benefit from knowledge in all disciplines. The supervisor will be competent in one area but the $\mathrm{PhD}$ student will have to train her/himself in the other discipline. The other constraint is related to the publication of the research. Although multiple journals have extended their scope to $\mathrm{N} \& \mathrm{~N}$, only a few are generalist. In this way, multidisciplinary studies cannot be published as a whole and as a full process of reflection. Even though they are justified by a problem-solving approach, they have to be split in order to fit an established discipline (see table 3).

\begin{abstract}
'When you're writing a thesis, it's much easier to write a thesis if you have a lot of publications, you know which I don't have unfortunately because of those difficulties. And there are other people that complain about the same. So, I don't think it's just me.' (PhD student, background in analytical chemistry).
\end{abstract}

<Please insert Table 3 about here>

\title{
4.4. Perception of the area of $N \& N$
}

The perception of these boundaries will, however, differ in function of the background of the scientists and the definition that is attached to the label nanotechnology. As mentioned earlier, nanotechnology is at the crossroads of many disciplines. The definition of nanotechnology 
from 1 to $100 \mathrm{~nm}$ is not enough to include or exclude scientists with different backgrounds into one homogeneous scientific community. Indeed, some works and thus knowledge are included in the area of nanotechnology without explicitly being named or labelled as such. So, depending on what the scientist considers as part of the area of nanotechnology, his perception of his own scientific boundary and those of nanotechnology will differ. Moreover, although nanotechnology is said to cross a multitude of scientific disciplines, a distinction is made between science and technology in order to separate the knowledge production and the application of this knowledge. So, multiple boundaries are perceived between science and the applications.

\begin{abstract}
'Nanoscience would evoke very much the scientific content. That wouldn't necessarily include engineering [...]. There is other stuff out there which is nanotechnology and has always been nanotechnology, we've just never labelled it nanotechnology. So a lot of paint, emulsion paint and so on will actually be on the nanoscale but we've never redefined that. Manufacturers in atomic force microscope are dealing with very much large components but they're building tool for nanoscience. That would fall into the category of nanotechnology.' (Lecturer)
\end{abstract}

The lack of clear definition and the difficulties regarding both the research and its publication lead young scientists to see themselves as either pioneers of a new and promising area of research or as not belonging to an established field. First, by seeing N\&N as a new area of research, they describe their practices as different from established disciplines such as physics, chemistry or biology. Integrating physical experiments into biological studies is the first step to new ways of doing research. Moreover, by being in a multidisciplinary environment and going to conferences dedicated to $N \& N$ or more especially to nanotoxicology, they tend to develop a proper identity and distance themselves from established disciplines.

\footnotetext{
'Nanoscience is in its child step, very basic science, no one knows properly if it can help or if it can be harmful. At some point when many more people will work on this, then definitely, different works will come together and give us a story.' (PhD student, background in toxicology)
} 
On the other hand, these practices that are not embedded in an established discipline and the non-alignment between the scientific disciplines, the practises and schools tend to create confusion when young scientists try to describe their discipline, what they are doing, and who they are.

'I would be a biologist, with a degree in chemistry, registered with school of physics.' (PhD student, background in applied chemistry)

These types of confusion are present among $\mathrm{PhD}$ students but not among senior researchers. Their research is linked with their previous and established background. Their perception of the area of $N \& N$ is related to their research and how they can relate it $N \& N$. They would tend to emphasise the enabling characteristics and the instruments rather than the scientific aspects (see Table 4).

\begin{abstract}
'I'm materials. Actually, do I define myself by: I'm laser physicist because originally I was working with laser in laser physics. Am I material? If I'm material, I'm chemical physicist, am I physical chemist? I am not physical chemist, I'm physical chemist. And certainly now, I am not nanoscientist. Maybe I'm too old to be a nanoscientist.' (Manager of the research centre)
\end{abstract}

$<$ Please insert table 4 about here $>$

\title{
5. DISCUSSION
}

This study was designed to answer the following research question: How do scientists involved in a scientific area crossing multiple scientific disciplines use multidisciplinary knowledge in order to create a new scientific outcome? This research is motivated by a need to deepen the understanding of scientific practices in a multidisciplinary context. Through an exploratory study, I looked at how scientists hosted by a single research group and with different scientific backgrounds practise multidisciplinarity in their day to day work. I first 
highlighted that the research group has developed a speciality in $N \& N$ based on internal capacities and stock of knowledge. Second, I showed that scientific boundaries are difficult to be cross and lead scientists to create local knowledge in order to produce a multidisciplinary scientific outcome. Finally, by engaging in multidisciplinary practices on a daily basis, scientists and young scientists in particular are torn between being pioneer of a new scientific area and have difficulties to locate themselves in their environment. Considering the theoretical framework and the findings, the discussion will based on two points: (1) scientific practices in a mutlidisciplinary context an $\mathrm{d}$ (2) convergence of scientific disciplines, and technological hubs.

First, practices were defined as 'equated with doing, concreteness, understanding, know-how and wholes' (Weick, 2003: 454). In the multidisciplinary context of N\&N, practices do not rely on the cumulative process of knowledge creation. Indeed, in a fast growing contexts, no basic body of knowledge have been clearly identified (Yanez et al., 2010). By bringing methods and theore-tical knowledge from a scientific discipline to another, scientists create local knowledge. So, as practices are not predetermined by theoretical foundations, they are created on a daily basis. This knowledge is not part of the cumulative process as they have to be over explained in order to make sense and to be accepted in the other disciplines. So, although incorporated in instruments, knowledge accepted in a community has to follow a similar process in order to be accepted in another one. In their classification of scientific statements, Latour and Woolgar (1979) describe the process through which an observation (Type 1 statement) will be assessed in order to be accepted or not in the scientific community (Type 5 statement). The local practices, or knowledge (Weick, 2003), that are created by using instruments from a scientific discipline have to go through the similar assessment in order to be accepted in another discipline. Moreover, although sometimes scientists move from one discipline to create a new sub-discipline (Shinn and Ragouet, 2000), the lack of 
established channels (Zucker et al., 2007), in other words multidisciplinary journals, might hinder the theorisation of these types of new practices and knowledge.

Second, the convergence of scientific disciplines is limited and the collaboration them is at a more multidisciplinary stage than an interdisciplinary one (Schummer, 2004a). Indeed, as mentioned ear-lier, both the specialisation of the laboratory and practices rely on established scientific disciplines and no strong ties, overlaps and integration can be strictly identified. So, multidisciplinarity is more suitable in order to characterise the movement of scientists between different areas of research (Shinn and Joerges, 2002; Shinn and Ragouet, 2000) than a real interdisciplinarity in scientific research. This point is related to the limited multidisciplinarity aspect of N\&N (Bassecoulard et al., 2007; Rafols and Meyer, 2007; Schummer, 2004b; Schummer, 2008). Therefore, some overlaps exist between

the parent disciplines and might lead to the creation of new sub-disciplines (Shinn and Ragouet, 2000) but the cross-fertilisation between the disciplines is not established enough to be named interdisciplinary research. However, all over the world micro- and nanotechnology centres have emerged (Kautt et al.,2007). While we have here focused on a research-oriented research group, in the global context described by the triple helix model (Leydesdorff, 2000; Leydesdorff and Etzkowitz, 1998; Leydesdorff and Meyer, 2007) more industry-oriented research groups and centres have also emerged (Kautt et al., 2007). We therefore question the boundaries that are set up by public funding in order to foster multidisciplinary research and the development of $\mathrm{N} \& \mathrm{~N}$ materialised by research centres, and the scientific boundaries that are present within these research centres. Although traditionally physical boundaries of the research centres match the cognitive boundaries of science, there is now a mismatch between the two. 
Knorr Cetina (1992) argues that the configurations of laboratories are shaped in relation to the work which goes on within the laboratory. In other words, depending on the type of research the laboratory can take different forms. The relation between the laboratory - physical and social structure - and the experiments - type of science - can be more or less intertwined. So, building on Knorr Cetina (1992) and by following Kautt et al.'s (2007) description of research centres - technology, aims (research or industry-oriented) and types of funding - I here argue that technological hubs can be characterised in terms applying a set of composite boundaries (Hernes, 2004) in order to have a much more precise picture of the different types of laboratory that are dedicated to nanotechnology. This will allow us to highlight the different research groups and centres to deepen the understanding about which scientific disciplines are present within the research centre or group, the type of collaboration that is undertaken within and with the outside of the laboratory, and the structure that receives the scientists. This should enlighten the different types of convergence and multidisciplinarity in N\&N.

\section{LIMITATIONS AND FUTURES RESEARCHES FUTURE OF ON N\&N}

Three main limitations of the study are here identified. First, the research took place in a research group that has been chosen for its endogenous attributes (Siggelkow, 2007). It hosts scientists with various backgrounds and the specialisation of the research group is the area of nanotoxicology which is characterised by the integration of physical characterisation to biological studies. Therefore, this single case presents idiosyncratic characteristics that can be avoided by performing a multiple case study (Eisenhardt, 1989). However, this case brings empirical data to the understanding of the multi-disciplinary aspect of N\&N. Second, boundaries are not static but are in constant construction and reconstruction (Hernes, 2004). This study does not capture the evolution of the boundaries over time and how individual 
challenge these boundaries. A more longitudinal approach has to be undertaken in order to clarify the evolution of collaboration in a multidisciplinary context. Third, the study focuses on scientific practices and does not fully take into account the funding and the expectations that are related to it which can influence the research and/or the specialisation of the lab.

\section{CONCLUSION}

This study contributes to a better understanding of nanotechnology by focusing on a research group qualified as technological hubs and that hosts scientists with various scientific backgrounds. The second insight to be gained from this study is that nanotechnology is at a multidisciplinary stage more than an interdisciplinary one. The collaboration between scientists from different disciplines can be understood by their scientific heritage and the barriers that are related to it, and how individuals use knowledge from another discipline in order to produce a new scientific outcome. It also suggests that nanotechnology can be further understood by focusing on co-existing boundaries and locus of multidisciplinarity.

\section{REFERENCES}

Avenel, E., Favier, A.V., Ma, S., Mangematin, V., Rieu, C., 2007. Diversification and hybridization in firm knowledge bases in nanotechnologies. Research Policy 36, 864-870.

Bassecoulard, E., Lelu, A., Zitt, M., 2007. Mapping nanosciences by citation flows: a preliminary analysis. Scientometrics $70,859-880$.

Bhat, J.S.A., 2005. Concerns of new technology based industries-the case of nanotechnology. Technovation 25, 457-462. 
Bonaccorsi, A., 2008. Search regimes and the industrial dynamics of science. Minerva 46, 285-316.

Bonaccorsi, A., Thoma, G., 2007. Institutional complementarity and inventive performance in nano science and technology. Research Policy 36, 813-831.

Bozeman, B., Laredo, P., Mangematin, V., 2007. Understanding the emergence and deployment of “nano”' S\&T. Research Policy 36, 807-812.

De Jong, W.H., Borm, P.J.A., 2008. Drug delivery and nanoparticles: applications and hazards. International Journal of nanomedicine 3, 133-149.

Eisenhardt, K.M., 1989. Building theories from case study research. Academy of Management Review 14, 532-550.

Gibbons, M., Limoges, C., Nowotny, H., Schwartzman, S., Scott, P., Trow, M., 1994. The New Production of Knowledge: The Dynamics of Science and Research in Contemporary Societies. Sage, London.

Gieryn, T., 1983. Boundary work and the demarcation of science from non-science: strains and interests in professional ideologies of scientists. American Sociological Review 48, 781795.

Gieryn, Y., 1999. Cultural Boundaries of Science: Credibility on the Line. Chicago University Press, Chicago, IL.

Glaser, B.G., Strauss, A.L., 1967. The Discovery of Grounded Theory: Strategies for Qualitative Research. Aldine, New York. 
Grodal, S., 2007. The Emergence of a New Organizational Field: Labels, Meaning, and Emotions in Nanotechnology, Dissertation. Stanford University.

Grodal, 2010. Meaning mechanisms in nanotechnology: expansion and contraction of field labels. Working Paper.

Heinze, T., Bauer, G., 2007. Characterizing creative scientists in nano-S\&T: productivity, multidisciplinarity, and network brokerage in a longitudinal perspective. Scientometrics 70, $811-830$.

Heinze, T., Shapira, P., Senker, J., Kuhlmann, S., 2007. Identifying creative research accomplishments: methodology and results for nanotechnology and human genetics. Scientometrics 70, 125-152.

Hernes, T., 2004. Studying composite boundaries: a framework of analysis. Human Relation 57, 9-29.

Kautt, M., Walsh, S.T., Bittner, K., 2007. Global distribution of micro-nano technology and fabrication centers: a portfolio analysis approach. Technology Forecasting \& Social Change $74,1697-1717$.

Linstone, H.A., 2011. Three eras of technology foresight. Technovation 31, 69-76.

Loveridge, D., Dewick, P., Randles, S., 2008. Converging technologies at the nanoscale: the making of a new world? Technology Analysis \& Strategic Management 20, 29-43.

Islam, N., Miyazaki, K., 2009. An empirical analysis of nanotechnology research domains. Technovation 30, 229-237. 
Kuhn, T.S., 1970. The Structure of Scientific Revolutions, 2nd ed. University of Chicago Press, Chicago (1st ed. 1962).

Klein, J.T., 2010. The taxonomy of interdisciplinarity. in: Frodeman, R., Klein, J., Mitcham, C. (Eds.), Oxford Handbook of Interdisciplinarity, Oxford University Press, Oxford.

Knorr Cetina, K., 1992. The couch, the cathedral, and the lab: on the relationship between experiment and laboratory science. in: Pickering, A. (Ed.), Science as Practice and Culture, Chicago University Press, Chicago, pp. 113-138.

Latour, B., 1987. Science in Action: How to Follow Scientists and Engineers Through Society. Harvard University Press, Cambridge, MA.

Latour, B., Woolgar, S., 1979. Laboratory Life: the Social Construction of Scientific Facts. Sage, London and Beverly Hills.

Lakatos, I., 1970. Falsification and the methodology of scientific research pro-grammes. in: Lakatos, I., Musgrave, A. (Eds.), Criticism and the Growth of Knowledge, Cambridge University Press, Cambridge, pp. 91-198.

Leydesdorff, L., 2000. The triple helix: an evolutionary model of innovations. Research Policy 29, 243-256.

Leydesdorff, L., Etzkowitz, H., 1998. The triple helix as a model for innovation studies. Science and Public Policy 25, 195-203.

Leydesdorff, L., Meyer, M., 2007. The scientometrics of a triple helix of university-industrygovernment relations. Scientometrics 70, 207-222. 
Merton, R., 1942/1973. The normative structure of science. in: Merton, R. (Ed.), The Sociology of Science: Theoretical and Empirical Investigations, University of Chicago Press, Chicago, IL, pp. 267-278.

Meyer, M., 2001. Patent citation analysis in a novel field of technology: an exploration of nano-science and nano-technology. Scientometrics 61, 163-183.

Meyer, M., 2007. What do we know about innovation in nanotechnology? Some propositions about an emerging field between hype and path-dependency. Scientometrics 70 (3), 779-810.

Miles, M.B., Huberman, M.A., 1994. Qualitative Data Analysis: an Expanded Sourcebook. Sage, London.

Nowotny, H., Scott, P., Gibbons, M., 2003. Mode 2 revisited: the new production of knowledge-introduction. Minerva 41 (3), 179-194.

Oberdörster, G., Oberdörster, E., Oberdörster, J., 2005. Nanotoxicology: an emerging discipline evolving from studies of ultrafine particles. Environmental Health Perspectives $113,823-839$.

Popper, K.R., 1970. Normal science and its dangers. in: Lakatos, I., Musgrave, A. (Eds.), Criticism and the Growth of Knowledge, Cambridge University Press, Cambridge, pp. 5158.

Porac, J., et al., 2004. Human capital heterogeneity, collaborative relationships, and publication patterns in a multidisciplinary scientific alliance. Research Policy 33, 661-678.

Porter, A.L., Youtie, J., 2009. How interdisciplinary is nanotechnology? Journal of Nanoparticle Research 11, 1023-1041. 
Rafols, I., Meyer, M., 2007. How crossdisciplinarity is bionanotechnology? Explorations in the speciality of molecular motors. Scientometrics 70, 633-650.

Roco, M.C., Bainbridge, W.S., 2002. Converging Technologies for Improving Human Performance: Nanotechnology, Biotechnology, Information Technology and the Cognitive Science. National Science Foundation, Arlington, VA.

Roco, M.C., 2005. International perspective on government nanotechnology fund-ing in 2005. Journal of Nanoparticle Research 7, 707-712.

Roco, M.C., 2008. Possibilities for global governance of converging technologies. Journal of Nanoparticle Research 10, 11-29.

Schmidt, J.C., 2008. Tracing interdisciplinarity of converging technologies at the nanoscale: a critical analysis of recent nanotechnosciences. Technology Analysis \& Strategic Management 20, 45-63.

Schummer, J., 2004a. Multidisciplinarity, interdisciplinarity, and patterns of research collaboration in nanoscience and nanot echnology. Scientometrics 59, 425-465.

Schummer, J., 2004b. Interdisciplinary issues in nanoscale research. in: Baird, D., Nordmann, A., Schummer, J. (Eds.), Discovering the Nanoscale, IOS Press, Amsterdam.

Schummer, J., 2008. From nano-convergence to NBIC-convergence: "The best way to predict the future is to create it'". in: Maasen, S., Kaiser, M., Kurath, M., Rehmann-Sutter, C. (Eds.), Deliberating Future Technologies: Identity, Ethic, and Governance of Nanotechnology, Heidelberg et al, Springer.

Seaton, A., Donaldson, K., 2005. Nanoscience, nanotoxicology, and the need to think small. The Lancet 365, 923-924 
Shinn, T., Joerges, B., 2002. The transverse science and technology culture: dynamics and roles of research-technology. Social Science Information 41, 207-251.

Shinn, T., Ragouet, P., 2000. Formes de division du travail scientifique et convergence intellectuelle. La recherche instrumentale. Revue Française de Sociologie 41, 447-473.

Siggelkow, N., 2007. Persuasion with case studies. Academy of Management Journal 50, $20-24$.

Sydow, J., Schreyögg, G., Koch, J., 2009. Organisational path-dependency: opening the black box. Academy of Management Review 34, 689-709.

Weick, K., 2003. Theory and practice in the real world. in: Tsoukas, H., Knudsen, C. (Eds.), The Oxford Handbook of Organization Theory, Oxford University Press, New York.

Yanez, M., Khalil, T.M., Walsh, S.T., 2010. IAMOT and education: defining a technology and innovation management (TIM) body-of-knowledge (BoK) for graduate education (TIM BoK). Technovation 30, 389-400.

Yin, R.K., 2009. Case Study Research: Design and Methods, 4th ed. Sage, Thousand Oaks, CA.

Zucker, L.G., Darby, M.R., Furner, J., Liu, R.C., Ma, H., 2007. Minerva unbound: knowledge stocks, knowledge flows and new knowledge production. Research Policy 36, 850-863. 
Table 1: Description of the interviewees

\begin{tabular}{lllll}
\hline \multicolumn{1}{c}{ Position } & $\begin{array}{c}\text { Number of } \\
\text { interviews }\end{array}$ & Post graduate diploma & PhD discipline & \multicolumn{1}{c}{ Topic } \\
\hline Research centre manager & 3 & physics & physics & laser physics \\
Lecturer & 3 & physics and chemistry & physics & carbon60 and fullerenes \\
Research group manager & 1 & physics and chemistry & biology & radiation biology \\
Postdoctoral researcher & 2 & physics & physics & carbon nanotubes \\
and laboratory manager & & biology & molecular biology & iron oxide nanoparticles \\
Postdoctoral researcher & 2 & analytical chemistry & nanoscience & mammalian cell toxicology \\
PhD student & 2 & applied chemistry & nanoscience & mammalian cell toxicology \\
PhD student & 2 & nanoscience & ecotoxicology \\
PhD student & 2 & toxicology & nanoscience & mammalian toxicology \\
PhD student & 2 & biochemistry & nanoscience & ecotoxicology \\
PhD student & 2 & toxicology & nanoscience & drug delivery \\
PhD student & 2 & toxicology &
\end{tabular}


Tables 2: Development of a specialisation in N\&N - Open codes and aggregates.

\begin{tabular}{|c|c|c|}
\hline Quotes & Open coding & Aggregates \\
\hline $\begin{array}{l}\text { 'I think this is a niche to be able to approach from the two angles, like } \\
\text { the physics, physic-chemical kind of characterisation and then the } \\
\text { toxicology.' }\end{array}$ & $\begin{array}{l}\text { Being specialised } \\
\text { into one area }\end{array}$ & \multirow{3}{*}{ Expertise } \\
\hline $\begin{array}{l}\text { 'Alpha I don't think is doing any toxicological study and Beta they are } \\
\text { more into like applications. Beta has started looking a bit at the } \\
\text { toxicological part but always it was more the application thing. } \\
\text { Gamma was parallel to us, to the application and the toxicological } \\
\text { part. If I put the Nanolab in that perspective Gamma are well } \\
\text { established, so as Beta and we are evolving.' }\end{array}$ & $\begin{array}{l}\text { Positioning the lab } \\
\text { with potential } \\
\text { competitors }\end{array}$ & \\
\hline $\begin{array}{l}\text { 'They had the facilities for cell culture that I needed as well as the } \\
\text { spectrometry and the expertise of that part. It was a good } \\
\text { opportunities for me that is why I took it. That was my main reasons } \\
\text { for coming to Nanotoxlab' }\end{array}$ & $\begin{array}{l}\text { Seeking an } \\
\text { expertise in a } \\
\text { specific area }\end{array}$ & \\
\hline $\begin{array}{l}\text { 'It's good to have Nanotoxlab recognised as a centre because it means } \\
\text { it's recognised as something unique and important and having unique } \\
\text { skills and equipment.' }\end{array}$ & $\begin{array}{l}\text { Benefiting from the } \\
\text { recognition }\end{array}$ & \\
\hline $\begin{array}{l}\text { 'The nano thing is more highlighted. Definitely it is some sort of } \\
\text { recognition. And the recognition is always needed is this field because } \\
\text { there are specific nano lab research centres. }\end{array}$ & $\begin{array}{l}\text { Looking for } \\
\text { recognition }\end{array}$ & Visibility \\
\hline $\begin{array}{l}\text { 'We are collaborating with Gamma and because we have the facilities } \\
\text { to do the eco part they don't.' }\end{array}$ & $\begin{array}{l}\text { Having specific } \\
\text { equipments }\end{array}$ & \\
\hline $\begin{array}{l}\text { 'That's why the funding was set up for my lab. [..] That specifically } \\
\text { bought the DLS, bought the ultra low temperature freezer that's what } \\
\text { the cells are in, bought the incubator, pretty much bought everything } \\
\text { in the lab.' }\end{array}$ & Need for funding & Facilities \\
\hline $\begin{array}{l}\text { 'We don't need more instruments. Whatever instruments we have, } \\
\text { they're already the best.' }\end{array}$ & $\begin{array}{l}\text { Working with } \\
\text { cutting edge } \\
\text { instruments }\end{array}$ & \\
\hline
\end{tabular}


Table 3: Scientific boundaries: Between heritage and adaptation - Open codes and aggregates

\begin{tabular}{|c|c|c|}
\hline Quotes & open coding & aggregates \\
\hline $\begin{array}{l}\text { 'I come from a very much physical background and physics tends to } \\
\text { question thing, why is that happening. Probably I want to take the } \\
\text { thing apart, and mix up the filter and arrange and stuff. They're just } \\
\text { happy with that and just leave it there. Whereas we want to understand } \\
\text { what it is doing it, the fundamental concept is behind, how you're } \\
\text { taking the measure.' }\end{array}$ & $\begin{array}{l}\text { Experiencing } \\
\text { different ways of } \\
\text { thinking }\end{array}$ & \multirow{3}{*}{$\begin{array}{l}\text { Scientific } \\
\text { heritage }\end{array}$} \\
\hline $\begin{array}{l}\text { 'I'm an analytical chemist, when I'm talking about the concentration } \\
\text { of something I refer to it as ppm which is part per million. A pure } \\
\text { chemist would use mole or molarity or the number of mole.' }\end{array}$ & $\begin{array}{l}\text { Having knowledge } \\
\text { depending on a single } \\
\text { scientific discipline }\end{array}$ & \\
\hline $\begin{array}{l}\text { 'I think that a chemist would probably more understand the molecular } \\
\text { biology than I ever will.' }\end{array}$ & $\begin{array}{l}\text { Being limited to cross } \\
\text { disciplinary } \\
\text { boundaries }\end{array}$ & \\
\hline $\begin{array}{l}\text { 'I characterise the nanoparticles here, the nanoparticles that I'm } \\
\text { using, their chemical structure, the characterisations, the size } \\
\text { measurement, the zeta potential measurement.' }\end{array}$ & $\begin{array}{l}\text { Using instruments as } \\
\text { multidisciplinary } \\
\text { knowledge }\end{array}$ & \multirow{3}{*}{ Adaptation } \\
\hline $\begin{array}{l}\text { 'It is generally agreed that they are certain measurement that should } \\
\text { be made for material. But, that's just our own group. Worldwide or } \\
\text { Europe, there is no protocols. I can't look up a protocol for } \\
\text { nanomaterials. Each group is starting to come across their own way of } \\
\text { measurement. We have our own ways, and they're other research } \\
\text { group that they their own certain ways. So at the moment it is } \\
\text { becoming knowledge of the different ways.' }\end{array}$ & $\begin{array}{l}\text { Creating local } \\
\text { practices }\end{array}$ & \\
\hline $\begin{array}{l}\text { 'I have no real experience with biology before I started my postgrad. } \\
\text { But my postgrad is a little dependent on biology. So I have a lot work } \\
\text { to do in that area because particularly from my perspective. Because I } \\
\text { am concerned about how toxic nanomaterials are. I need to really } \\
\text { understand how biological systems react to something. I just took a lot } \\
\text { of learning when I started my postgrad. I just had to do a lot of study } \\
\text { just to get up to the speed on biology.' }\end{array}$ & $\begin{array}{l}\text { Filling knowledge } \\
\text { gap in order to } \\
\text { integrate } \\
\text { multidisciplinary } \\
\text { knowledge }\end{array}$ & \\
\hline $\begin{array}{l}\text { 'I have trouble publishing papers. I've written a paper that has shown } \\
\text { that such and such material is toxic when it comes out of this material } \\
\text { here. [...] Now, when I send that to a journal, the journal will say, it's } \\
\text { not really a toxicology paper it's a material science paper. And I send } \\
\text { it to a materials journal and they will say there is too much toxicology. } \\
\text { It's not a materials journal paper, you know. So, I find it difficult to } \\
\text { publish some studies. One of the ways that I can go above that is the } \\
\text { split the study down into small chunks.' }\end{array}$ & $\begin{array}{l}\text { Having troubles to } \\
\text { produce a scientific } \\
\text { outcome accepted by } \\
\text { the community }\end{array}$ & \multirow[t]{2}{*}{ Constraint } \\
\hline $\begin{array}{l}\text { 'My supervisors are great, I'm not saying that they're not great but I } \\
\text { do feel as I said some of the other guys who the toxicology or even the } \\
\text { biology experience. All of my supervisors are physicists by trade.' }\end{array}$ & $\begin{array}{l}\text { Working an area that } \\
\text { does not benefit from } \\
\text { cumulative } \\
\text { knowledge }\end{array}$ & \\
\hline
\end{tabular}


Table 4: Perception of the area of N\&N - Open codes and aggregates

\begin{tabular}{l} 
Quotes \\
\hline 'Nanotechnology simply is a way of describing the evolution of \\
material and research in life the sciences enable by the ability to see \\
and manipulate material at the nanoscale; just simply, moving on the \\
research to a different dimension.' \\
'Suppose you have been working all your life at hundred and twenty \\
nanometres. You miss everything, you can't call yourself a \\
nanoscientist, you can't apply for all these funding, you can't publish \\
in all these journals because you're at hundred twenty nanometres. \\
That's a joke, nobody really draws a line.'
\end{tabular}

'The main focus in toxicology is nano-particles because is such a new area and they just grow more and more. [...] I mean when I was in college there was no talk about nanoscience, nanoparticles, nanotechnology. It just wasn't happening. But now, it's just become so new, there is so much research now.'

'I think nano and nanotechnology and everything is very different from the other kind of strands of science because pure development is chemistry, pure toxicology is biological. A lot of development of semi conductors and stuff, that's all physics based whereas nano exists in all of the three main disciplines. [...]. It's unique in that sense.'

'I get the feeling that there is an increasing identification, it's not just nano but it's particularly in nano and almost maybe a pride as well. We're not physics. Not just in the nano-field but in other area as well, there is an increase of interdisciplinary. So i get the feeling that this increase we get in general pride that: we're not physics, we're not chemistry, we're interdisciplinary.'

'I'm registered with the school of physics so I'm on paper I'm a physicist now but I'm a toxicologist really. I find it easy to talk to them all. My background is chemist so I consider myself as a chemist but because the Nanotoxlab group is part of the school of physics, so if someone would ask me where do you work I say the school of physics, so therefore I am a physicist. However I am not, I'm a toxicologist working in the school of physics. So I'm like a biologist who is actually a chemist but works in the school of physics.'

'People ask me what I do and it is really frustrating because if you say nanotechnology maybe 30\%, 40\% of people know what it is. But if you try to explain that I am a chemist but I use nanomaterials and I do physical things, measure them biologically and... They're kind of like Jesus no, she's confused, she doesn't know what she does.'

'Hopefully after older kind of scientist, new researchers are coming and wouldn't have problem to work with one or another. It is not a personal things, it is political limits. With another student [...] that would be the same. We are chemist, so nobody wants to hire a chemist who has a PhD in biology because they're not a specialist.'

\section{Open coding}

Aggregates

Describing N\&N as

technological

evolution

Discussing the

standard

No standard

definition of

N\&N

\section{Seeing N\&N as} growing and promising area of research

Describing N\&N as an indenpendent area of research

\section{Pioneer}

Developing a proper identity

\author{
Having difficulties to \\ be described when \\ there are no \\ established standards
}

Justifying a multidisciplinary Confusion work

Being concern about finding a place with a multidisciplinary background 